\title{
TRANSDERMAL OF ATENOLOL VIA MICROEMULSIONS
}

\author{
AHMAD AJWAD TALHOUNI ${ }^{1}$, JAMAL ALYOUSSEF ALKRAD ${ }^{*}$, MANAF MOHAMMED AL-DABBAGH ${ }^{1}$, HUSAM \\ ABAZID ${ }^{2}$, SAMER HASAN HUSSEIN-AL-ALI ${ }^{1}$
}

1Faculty of Pharmacy, Isra University, PO Box 22 and 23, Amman, Jordan, ${ }^{2}$ Faculty of Pharmacy, Applied Science Private University, Amman, Jordan

Email: jamal.alkrad@iu.edu.jo

Received: 01 Oct 2018, Revised and Accepted: 30 Jan 2019

\section{ABSTRACT}

Objective: Developing novel non-ionic microemulsions (MEs) for transdermal of atenolol as satisfactory alternative drug delivery systems for the oral route.

Methods: Seven MEs were developed then checked for encapsulation of atenolol using Fourier Transform Infrared Spectroscopy (FTIRspectroscopy) 0, isotropy, droplet sizes, rheological properties and transdermal flux using Franz diffusion cell. Furthermore, two MEs with best flux values were selected for bioavailability evaluation after transdermal application over rat's skin.

Results: The results showed that the MEs complies with colloidal systems properties. Also, the developed MEs were stable throughout the study, ideal viscous systems with droplet sizes below $500 \mathrm{~nm}$ and isotropic. Besides, FTIR-spectra could reveal the structure of the MEs and encapsulation of atenolol inside the dispersed phase. Moreover, the flux values of atenolol in MEs through rat's skin varied with different factors such as atenolol concentration, MEs's composition, and zetapotential. The highest flux value of the developed systems was $243.5 \pm 16.3 \mu \mathrm{g}$. $\mathrm{cm}^{-2}$. $\mathrm{h}^{-1}$. Furthermore, the in vivo results showed that using the two tested microemulsions maximum plasma levels of atenolol $5.22 \pm 0.43$ and $4.06 \pm 0.15 \mathrm{mg} \mathrm{ml}^{-1}$ at 8.18 and $3.64 \mathrm{~h}$ respectively could be achieved.

Conclusion: The developed microemulsions can be promise formulations for transdermal administration of atenolol as alternative for oral tablets.

Keywords: Atenolol, Transdermal, Microemulsions

(C) 2019 The Authors. Published by Innovare Academic Sciences Pvt Ltd. This is an open access article under the CC BY license (http://creativecommons.org/licenses/by/4.0/) DOI: http://dx.doi.org/10.22159/ijap.2019v11i2.30089

\section{INTRODUCTION}

Atenolol is a $\beta 1$-selective adrenergic blocking agent. It is widely used in the management of hypertension as monotherapy or in combination with other classes of antihypertensive agents [1-4]. Atenolol subjects to extensive first-pass hepatic metabolism and has an absolute oral bioavailability of about 50-60\%. Moreover, it was reported that, in the case of oral administration, atenolol can induce side effects such as diarrhea, ischemic colitis and mesenteric arterial thrombosis [5-8]. Transdermal application of a drug such as atenolol can lower the total daily dose and eliminate the gastrointestinal side effects. Also, the ease and self-medication can improve the patient compliance $[8,9]$. The short biological half-life $(2.8-7.4 \mathrm{~h})$ and lower value of molecular weight $\left(266 \mathrm{~g}\right.$ mole $\left.^{-1}\right)$ renders atenolol as an ideal candidate for transdermal drug delivery systems [10].

Many studies investigated the transdermal of atenolol using iontophoresis and chemical penetration enhancers [11-15]. Other studies evaluated the transdermal of atenolol such as using gel formulation, ethylene-vinyl acetate matrix or hydroxyl propyl methyl cellulose and ethyl cellulose matrix [16-18].

Newtonian rheological properties and high penetration enhancing the capacity of microemulsions (MEs) make them ideal carriers for transdermal as well as oral use [19-22]. Only one study was reported about in vitro investigation of the transdermal of atenolol using W/O microemulsion as a carrier. In this study, many lipophilic surfactants such as capmul GM050, caprol ET, lauroglycol 90 were screened to evaluate their propensity for emulsification of the aqueous phase to optimize atenolol loading [23]. The present study aimed to develop novel colloidal delivery systems using nonionic surfactants to enable and improve the transdermal application of atenolol and evaluate their bioavailability in vitro and in vivo.

\section{MATERIALS AND METHODS}

\section{Materials}

Atenolol was offered from a local company (United Pharmaceutical Manufacturing Co.). Ethanol HPLC grade was purchased from scientific and chemicals supplies LTD (Bilston, UK). Methanol HPLC grade was purchased from Fulltime (Anqing, China). Water for HPLC was purchased from LabChem (Zelienople, USA). Dimethyl sulfoxide (DMSO) was purchased from AZ Chem (Ontario, Canada). Sorbitan monolaurate (Span $\left.{ }^{\circledR} 20\right)$ and Poloxyethylenesorbitan. Mono-oleate (Tween ${ }^{\circledR} 80$ ) were purchased from SIGMA (Lyon, France). Citric acid (CA) and Isopropyl Myristate (IPM) were purchased from Merck (Darmstadt, Germany).

\section{Instruments and methods}

\section{Microemulsions (MEs) preparation}

MEs were prepared by the titration method [24]. Atenolol was dissolved in the hydrophilic phase composed of a mixture of water and ethanol or water, ethanol and DMSO. Two ml of IPM was added to atenolol solution. Either span 20 or mixture of span 20: tween 80 (3:2) were added dropwise with continuous stirring over magnetic stirrer to the lipophilic and hydrophilic phase mixture until a clear microemulsion was formed. The added amounts of surfactants were recorded. Compositions of the developed microemulsions are listed in table 1.

\section{Pseudo-ternary phase diagrams of microemulsion systems}

A pseudo-ternary phase diagram was plotted to find the existence area of MEs. Another three-phase diagram for MEs with $100 \mathrm{mg}$ atenolol was accomplished for testing the influence of atenolol on this area Formulations were made using three components which are the hydrophilic phase, lipophilic phase, and surfactants. Each phase forms one face of the triangle. The formulations were made with fractions of the three components according to crossing points which formed by plotting three parallel lines to the three faces of the triangle. More formulations were made between the cross points on the border of MEs area. After mixing, clear and stable formulations were identified to be MEs [24].

\section{Viscosity measurement}

An electric Rheometer made by Anton Paar, universal tool, model MCR 301 (Ostfildern, Germany) was used to determine the viscosity and rheological properties of MEs. Rheograms were established for the MEs with increasing and decreasing shear force at $25{ }^{\circ} \mathrm{C}$ on the bob and cup viscometers. 
Table 1: Composition of different developed MEs containing atenolol.

\begin{tabular}{|c|c|c|c|c|c|}
\hline MEs & $\begin{array}{l}\text { Lipophilic phase } \\
\text { (IPM) (ml) }\end{array}$ & Hydrophilic phase (ml) & $\begin{array}{l}\text { Atenolol } \\
\text { Amount (mg) }\end{array}$ & $\begin{array}{l}\text { Surfactant amount } \\
(\mathrm{ml})\end{array}$ & $\begin{array}{l}\text { Atenolol concentration } \\
\left(\mathrm{mg} \cdot \mathrm{ml}^{-1}\right)\end{array}$ \\
\hline ME600ts & 2 & 3.9 (Eth: W) (70:30) & 600 & $2.2(\mathrm{~T}: \mathrm{S})(3: 2)$ & 74.07 \\
\hline ME800ts & 2 & 5.1 (Eth: W) (70:30) & 800 & 3.1 (T: S) (3:2) & 78.43 \\
\hline ME1000-0.1CA & 2 & 4.5 (Eth: W) (70:30) 0.1M CA & 1000 & 2.9 (T: S) (3:2) & 106.38 \\
\hline ME900-1CA0.7 & 2 & 1.6 (Eth: W) (70:30) 1M CA & 900 & 0.1 (T: S) (3:2) & 243.24 \\
\hline ME900-1CA0.3 & 2 & 3 (Eth: W) $(30: 70)$ 1M CA & 900 & $1.4(\mathrm{~T}: \mathrm{S})(3: 2)$ & 140.62 \\
\hline ME1000dmso-s & 2 & 5 (Eth: W: DMSO) $(70: 15: 15)$ & 1000 & $3.7 \mathrm{~S}$ & 93.45 \\
\hline ME1000dmso-ts & 2 & $\begin{array}{l}5 \text { (Eth: W: DMSO) } \\
(70: 15: 15)\end{array}$ & 1000 & 2.9 (T: S) (3:2) & 101.01 \\
\hline
\end{tabular}

Eth: ethanol, w: water, DMSO: Dimethyl sulfoxide, IPM: Isopropyl Myristate, CA: citric acid, T: Tween 80, S: Span 20.

\section{Droplet size measurement (Zeta-potential measurement)}

A laser doppler electrophoresis was carried out on the microemulsions with a Zeta-sizer made by Microtrac (Pennsylvania, USA) equipment which is capable of measuring particle size ranging between $0.8 \mathrm{~nm}$ to $6.54 \mu \mathrm{m}$, Zeta potential range- 125 to $+125 \mathrm{mV}$. The sample was introduced into the apparatus cell without dilution as the formation of microemulsions depends on the concentration. Samples were measured at a temperature of $32^{\circ} \mathrm{C}$ without filtration.

\section{Polarized microscope}

A polarized microscope model ML9030 made by MEIJI techno (Saitama, Japan) was used for testing the isotropy of the microemulsions.

\section{Fourier transform infrared spectroscopy (FTIR) measurements}

The encapsulation of atenolol, as well as the structure of the MEs, was assessed by recording spectra by FTIR-spectrometer UATR Two, Li600301 spectrum made by Perkin Elmer in LIantrisant, UK for each single component, ME with atenolol and ME without atenolol. The FTIRspectra were measured at wave numbers between 450 and $4500 \mathrm{~cm}-1$.

\section{Preparing rat's skin}

Wistar male rats were purchased originally from the University of Jordan and fertilized at an animal house at Isra University. All the procedures were carried out in harmony with the NIH guidelines for the care and use of laboratory animals which were approved by the Animal Ethics Committee of Isra University. The rats were shaved carefully before executing. The adipose tissues were removed from the peeled skin and excised to small pieces to fit with Franz diffusion cell surface area (with the diameter a bit larger than $10 \mathrm{~mm}$ ) then were washed with buffer and stored in a deep freeze at a temperature below than-70 ${ }^{\circ} \mathrm{C}$.

\section{In vitro study of transdermal of atenolol using franz cell}

Franz diffusion cell is usually used for studying drug permeation through excised animal's skin [25]. Three Franz diffusion cells made by Orchid scientific in India $(10 \mathrm{~mm}$ diameter, $5 \mathrm{ml}$ acceptor volume) were used at the same time to study the transdermal of atenolol in MEs for each formulation. The cells were connected with the circulatory water bath to adjust the temperature of the cells at $32 \pm 0.1^{\circ} \mathrm{C}$. The frozen rat's skin pieces were thawed in a water bath at $32{ }^{\circ} \mathrm{C}$ immediately before using it in Franz-diffusion cells. The skin pieces were fixed directly over the acceptor compartment medium in contact with the acceptor medium. The acceptor compartment was filled with $5 \mathrm{ml}$ of $75 \%$ methanol in water. Only $0.2 \mathrm{ml}$ of each microemulsion was allocated over the skin using an insulin syringe. Half $\mathrm{ml}$ samples were withdrawn from the acceptor's orifice after 1 , $3,5,7$ and $24 \mathrm{~h}$ for analyzing the penetrated drug through the skin using HPLC. Each time withdrawn samples were replaced by $0.5 \mathrm{ml}$ of the same acceptor medium.

\section{In vivo study of transdermal of atenolol in rats}

Half $\mathrm{ml}$ of each of ME1000dmso-sor ME1000-0.1CAwas applied over shaved area of $4 \mathrm{~cm} 2$ on the back of each of 4 rats weighing $270-300 \mathrm{~g}$ for each formulation. Blood samples $(0.5 \mathrm{ml})$ were collected from the rats periodically after $1,3,7.11,15,19$, and $24 \mathrm{~h}$ in EDTA-blood-tubes. The blood samples were centrifuged at $4000 \mathrm{rpm}$ at $4{ }^{\circ} \mathrm{C}$ for $20 \mathrm{~min}$. The plasma portions were transferred into new tubes then $1 \mathrm{ml}$ of ethanol was added to each tube. The tubes were centrifuged at a rate of 8000 $\mathrm{rpm}$ at $4{ }^{\circ} \mathrm{C}$ for $20 \mathrm{~min}$. The supernatant was filtered through $0.45 \mu \mathrm{m}$ filter and transferred to HPLC sample tube for analysis.

\section{Atenolol analysis using a high-pressure liquid chromatography (HPLC) method}

Analysis was performed using chromatographic system of Thermo Scientific, Dionex Ultimate 3000 HPLC made in Germering, Germany connected with diode array detector using suitable standards. The samples were injected with a volume of $20 \mu$ into the mobile phase of $70 \%$ methanol at a flow rate of $0.5 \mathrm{ml} / \mathrm{min}$ and separated in column system C18 $\left(4.6^{*} 250 \mathrm{~mm}\right)$. The detection was carried out at a wavelength of $224 \mathrm{~nm}$ [26]. A calibration curve was established for concentrations of $0.05,0.1,0.2,0.4,0.8,1$ and $2 \mathrm{mg}$. ml- 1 to determine the amount of penetrated atenolol through the skin and in plasma.

\section{Pharmacokinetic and statistical analysis}

Tests were triplicated then the mean and standard deviation values calculated. Origen program was used for statistical evaluation with a confidence interval of $95 \%$. Jss is the steady-state flux is estimated from the slope at the steady state line (eq1) of plotting the cumulative penetrated amount per $\mathrm{cm}^{2}(\mathrm{Q} / \mathrm{A})$ against the time $(\mathrm{t})$ as in eq. 1 [27]:

$$
Q / A=J_{s s} t
$$

Where: A: skin surface area and Q: the cumulative mass penetrating a membrane.

The absorption rate constant, elimination rate constant and area under the curve were estimated from plasma level against time curve using pheonix ${ }^{\circledR}$ program (Phoenix Version 8.0, Certara, L. P.) by applying one compartment open model.

\section{RESULTS}

\section{HPLC method and the calibration curve}

The plotted calibration curve for measured areas under the curve against the concentrations of atenolol for concentrations between $0.05-2 \mathrm{mg} / \mathrm{ml}$ (fig. 1A) showed linearity of $99.9 \%$ and regression standard deviation of $3.4 \%$. The detection limit was extremely lower than $0.05 \mathrm{mg}^{-1} \mathrm{ml}^{-1}$ (the lowest concentration in the calibration curve) as the signal height ratio of atenolol to the noise markedly higher than 9 [28].

The straight line equation number (eq. 2) was adopted to calculate of penetrated atenolol amount:

$$
A=1159.47 \mathrm{C}+64.56
$$

Where: A: Area under the peak and C: Atenolol concentration.

For estimating the total amount of penetrated Atenolol the following developed equation (eq. 3) was developed:

$$
A T_{\text {amount }}=\left[\frac{(A-64.52)}{1159.46} * 5\right]+\left(0.1 A T_{\text {previous-amount }}\right)
$$

\section{Three phase diagrams (Pseudoternary diagram)}

The three-phase diagrams were established for MEs composed of IPM, water, ethanol and a mixture of tween 80: span $20(3: 2)$ without atenolol (fig. 2A) and with $100 \mathrm{mg}$ atenolol (fig. 2B). 


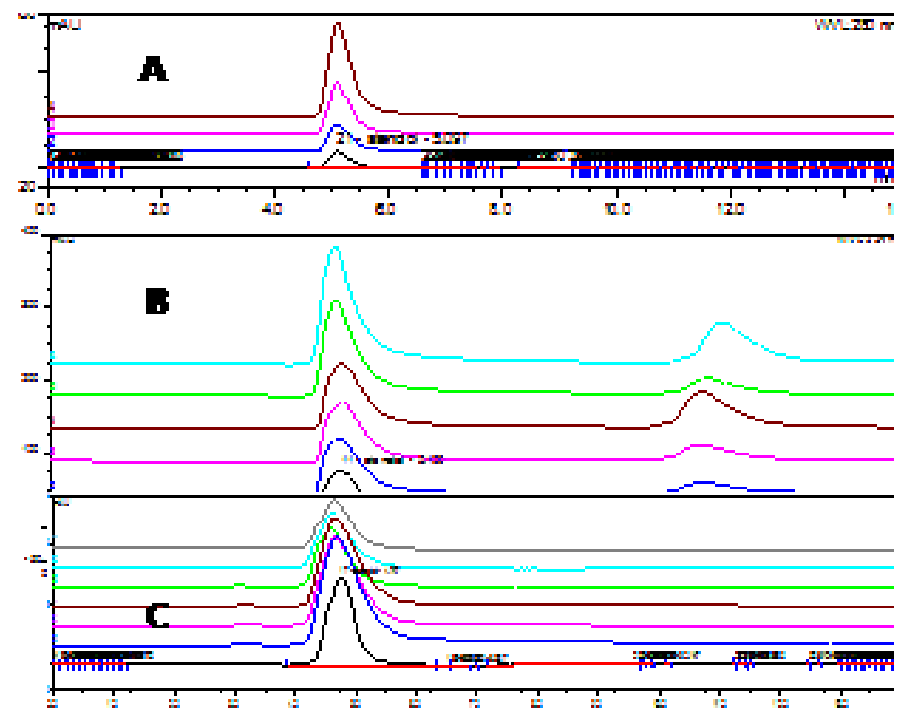

Fig. 1: Chromatograms of atenolol using HPLC A: in standard solutions for concentration between 0.05-2 mg/ml; B: in samples taken from Franz diffusion cell after 1-24 h; C: in blood samples after transdermal application between 1-24 h

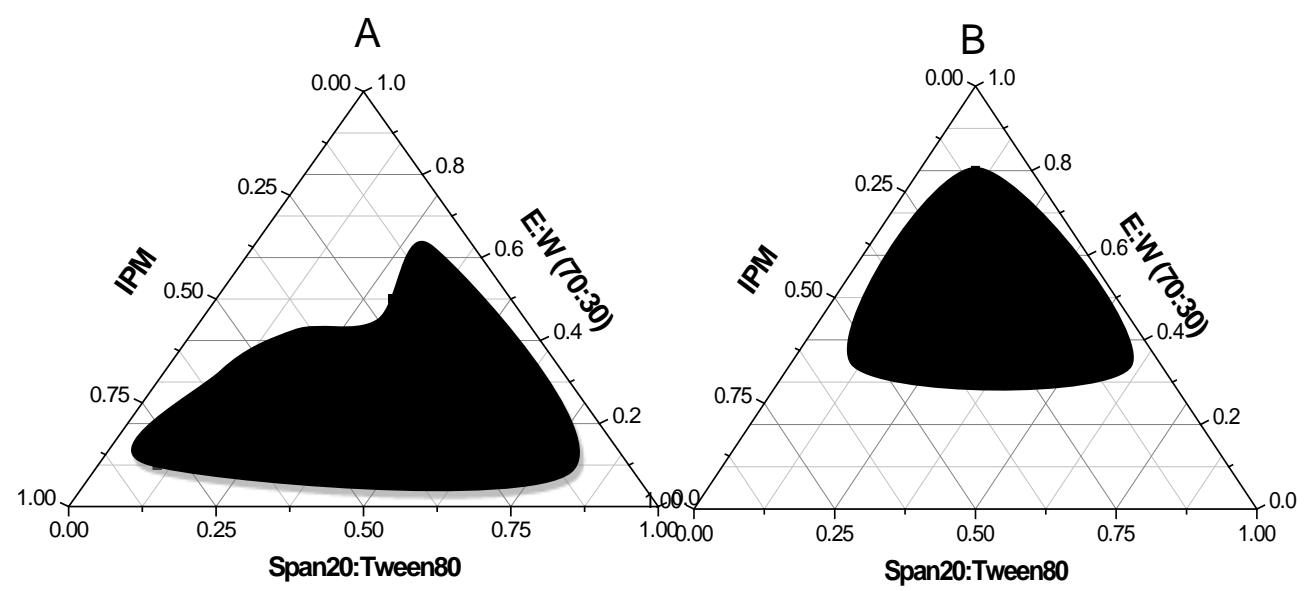

Fig. 2: Three phase diagrams of microemulsions (MEs) composed of IPM, water and a mixture of span 20: tween 80 (2:3) A: without atenolol; B: with atenolol

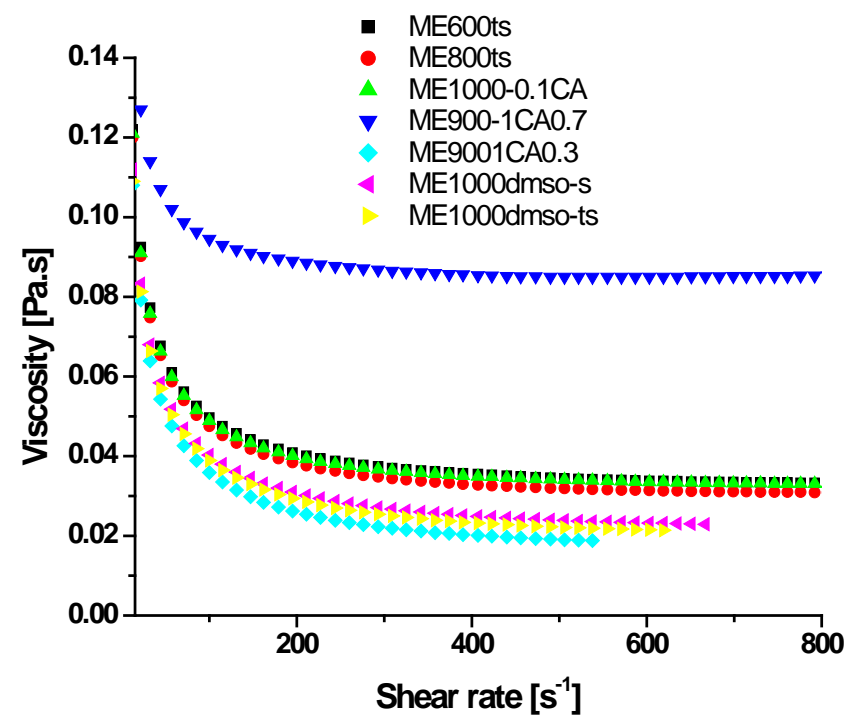

Fig. 3: Rheograms of developed MEs containing atenolol 
The area of clear MEs free of atenolol was estimated at fractions more than 0.6 of IPM and less than 0.6 of hydrophilic phase. After addition of $100 \mathrm{mg}$ of atenolol this area of ME was shifted to fractions less than 0.6 of IPM, more than 0.4 of hydrophilic phase and less than 0.6 of the surfactants. Consequently, the MEs containing atenolol consumed less surfactants amounts and solubilized higher hydrophilic phase fractions.

\section{Rheological properties}

The rheological properties were determined using the bob and cup instrument with increased shear rate for different systems and the results are represented in fig. 3 . The rheograms of different formulations show that the shear rate against the viscosity was constant. Accordingly, all the systems exhibited Newtonian characteristics.

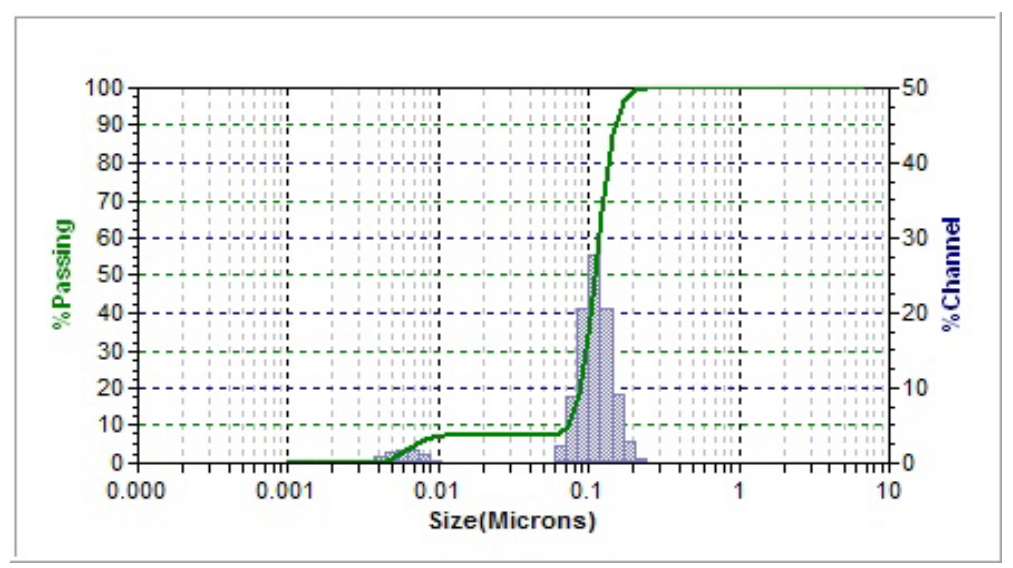

Fig. 4: Droplet size distribution curve of the ME1000 0.1CA using Zeta sizer

Table 2: The measured mean droplets sizes, zata potential and polydisperisty index (PDI) of different formulated microemulsions using Zeta-sizer

\begin{tabular}{llll}
\hline ME & Mean droplet size (nm) & PDI & Zeta potential [mv] \\
\hline ME600ts & $270.1 \pm 275$ & 10.88 & 10.72 \\
ME800ts & $163.6 \pm 60.4$ & 6.20 & 12.29 \\
MEtsfree atenolol & $52.2 \pm 19.4$ & 2.14 & -0.55 \\
ME1000-0.1CA & $107.4 \pm 28$ & 8.53 & 0.54 \\
ME900-1CA0.7 & $557 \pm 112$ & 0.16 & 0.30 \\
ME900-1CA0.3 & $550 \pm 145$ & 0.27 & 3.02 \\
MECA free Atenolol & $162.9 \pm 56.1$ & 0.51 & 1.83 \\
ME1000dmso-s & $378 \pm 138$ & 1.74 & 0.55 \\
ME1000dmso-ts & $320 \pm 321$ & 0.56 & 4.29 \\
MEdmso free Atenolol & $139.2 \pm 41.8$ & 16.8 & \\
\hline
\end{tabular}

Data given in this table is presented as mean $\pm S D, n=3$, SD: Standard deviation, PDI: Polydispersity index

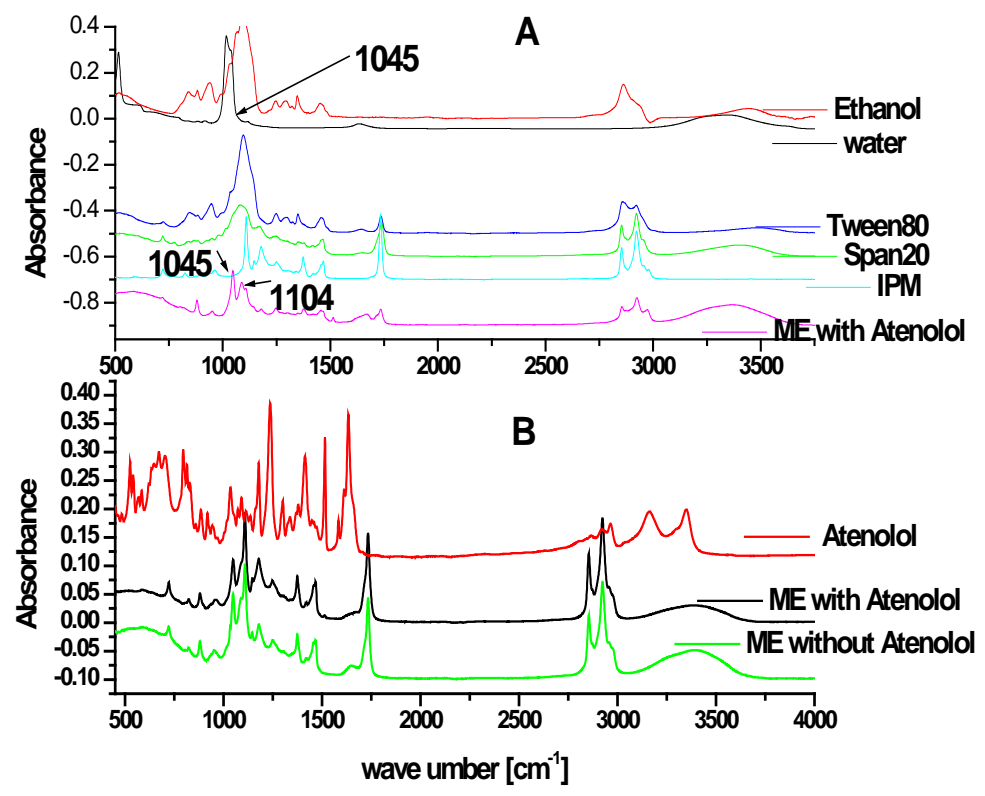

Fig. 5: FTIR-spectra (Fourier transform infrared) of A: pure components which used in formulation the microemulsions atenolol,; B: microemulsion with atenolol and microemulsion without atenolol 


\section{Droplet size measurement}

The results of zeta sizer (fig. 4) including the mean zeta, zeta potential droplets size and poly disparity index of the MEs with atenolol are summarized in table 2 .

Loaded systems with atenolol containing only water and ethanol showed 270, 163 and high polydispersity index. Using $0.1 \mathrm{M}$ citric acid solution reduced the droplet size to $107 \mathrm{~nm}$ in ME1000-0.1CA. However, droplets sizes were around $500 \mathrm{~nm}$ when $1 \mathrm{M}$ citric acid solution was used in ME1000-1CA0.7 and ME1000-1CA0.3 with relatively low polydispersity index and zeta potential. Also, by means of DMSO as penetration enhancer increased the concentration of atenolol in MEs as well as the droplets sizes to exceed $300 \mathrm{~nm}$. Measurements of the same three systems free of atenolol showed smaller droplet size in comparison to loaded systems with atenolol

Incorporation of atenolol in the ME600st and ME800st increased the zeta potential with increasing atenolol concentration from negative in case of free atenolol system to 10.7 and $12.2 \mathrm{mV}$ respectively. Addition of citric acid and DMSO neutralized the effect of atenolol and these MEs showed low zeta potential. However, using span 20 alone showed lower zeta potential compared to span 20 and tween 80 systems containing DMSO. Also, the decrease in ethanol fractions and an increase in water factions in system ME1000-1CA0.3 led to an increase the zeta potential compared to system ME1000-1CA0.7. Moreover, free atenolol ME containing DMSO showed high zeta potential $(16 \mathrm{mV})$ in comparison to other free atenolol MEs.

\section{Studying of atenolol encapsulation using Fourier transform infrared spectroscopy (FTIR)}

FTIR was used for studying the structure of MEs. The spectra of the different pure single ingredient used in the formulation of ME are represented in fig. 5A. Also, the spectra of ME with atenolol, ME without atenolol and atenolol are represented together in fig. 5B.

The different detected bands of the different components of MEs and their chemical bonds assignment are listed in table 3 [29].

Table 3: The most important detected bands of the different components of MEs and their chemical bonds assignments

\begin{tabular}{ll}
\hline Bands (cm-1) & Assignment \\
\hline $450-830$ which observed in ME, tween 80 and span 20 spectra & C-C and C-H bending \\
1045 & C-O stretching of Ethanol \\
1104 & C-O stretching of IPM \\
1092 in tween 80 and 1088 in span20 spectra & C-O stretching \\
& (disappeared to be weaker bands in IPM at 1118 and $1189 \mathrm{~cm}^{-1}$ in ME spectra) \\
$1720-1740$ & C=O ester group stretching of IPM \\
2700 to 3000 & C-H stretching of IPM \\
$3100-3671$ & OH, C-H stretching and bending \\
\hline
\end{tabular}

ME-spectrum was similar to IPM-spectrum which represents the outer phase of the ME except for the band between 2700-3000 which is possibly related to carbon chains of span 20 and tween 80 . The declining of $\mathrm{C}-\mathrm{O}$ stretching and appearing $\mathrm{C}-\mathrm{H}$ stretching indicates that sorbitol ring and an ester bond in tween 80 and span 20 oriented to inside the hydrophilic phase where carbon chains of the side groups oriented to the outer surface of the droplets in the outer phase. Moreover, FTIR-spectra of MEs with and without atenolol were similar and the bands of atenolol disappeared from ME-spectrum with AT. However, C-O stretching at wavelength $1045 \mathrm{~cm}^{-1}$ of ethanol appeared in ME-FTIR-spectrum near of C-O stretching of IPM.

\section{Transdermal studying using Franz diffusion cell}

Seven MEs containing atenolol were developed to study the transdermal of atenolol using MEs as carriers. Ethanol was used as a cosolvent in the formulation. Also, 0.1 and $1 \mathrm{M}$ citric acid solutions were added to the hydrophilic phase as a buffering agent to improve the solubility of atenolol in the hydrophilic phase in three of the developed MEs. Besides, the effect of DMSO as penetration enhancer atenolol was studied in two other MEs; one of them was stabilized with span 20 and the second with mixture of tween 80 and span 20 .

The in vitro transdermal testing for atenolol was performed using Franz diffusion cell through shaved rat's skin over $24 \mathrm{~h}$. The penetrated atenolol was quantified by removing $0.5 \mathrm{ml}$ samples from the acceptor and analyzing the musing HPLC (fig. 1B).

Penetrated atenolol amounts per $\mathrm{cm}^{2}$ were assessed over $24 \mathrm{~h}$ and the cumulative measured amounts per $\mathrm{cm}^{2}$ plotted against the time. Transdermal profiles for different formulations are represented in fig. 6.

The Flux (Jss) and lag time (tlag) were calculated from the slope and from intersect with time axis respectively of the line at steady state (eq.1). The results are tabulated in table 4 .

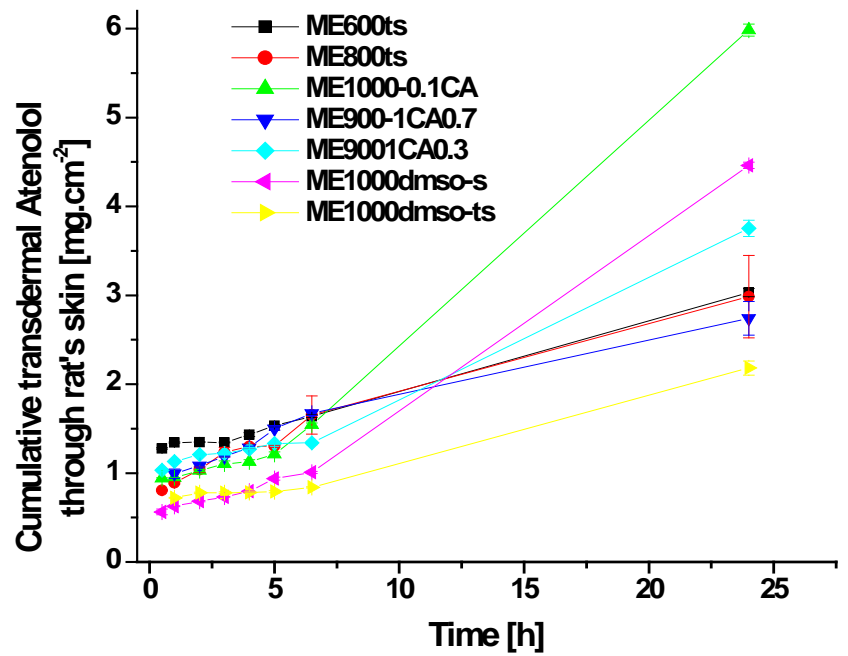

Fig. 6: Cumulative transdermal of atenolol from different formulated MEs over $24 \mathrm{~h}$ using Franz diffusion cell. Data given in this fig. is presented as mean $\pm S D, n=3, S D$ : Standard deviation 
Table 4: The flux of different formulated microemulsions (MEs) through rat's skin using Franz diffusion cell

\begin{tabular}{|c|c|c|}
\hline MEs & Flux (Jss) $\mu \mathrm{g} . \mathrm{cm}^{-2} \cdot \mathrm{h}^{-1}$ & Tlag (h) \\
\hline ME600ts & $81.9 \pm 2.28$ & 0.8 \\
\hline ME800ts & $111.8 \pm 5.7$ & 0 \\
\hline ME1000-0.1CA & $243.5 \pm 16.3$ & 3.5 \\
\hline ME900-1CA0.7 & $123.3 \pm 19.2$ & 0 \\
\hline ME900-1CA0.3 & $111.7 \pm 42.1$ & 2.4 \\
\hline ME1000dmso-s & $190.3 \pm 21.3$ & 2.4 \\
\hline ME1000dmso-ts & $67.9 \pm 14.8$ & 2.6 \\
\hline
\end{tabular}

Data given in this table is presented as mean $\pm S D, n=3$, SD: Standard deviation

Tlag: lag time ME1000-0.1CA had the highest flux where the ME1000dmso-s had the second value of flux among developed microemulsions. ME800ts which has a similar composition as ME600ts but higher concentration showed an increase in flux from 81.9 to $111.8 \mu \mathrm{g} . \mathrm{cm}^{-2}$. $\mathrm{h}^{-1}$. However, stabilization of microemulsion using span 20 and tween 80 in ME1000dmso-ts with the aid of DMSO as penetration enhancer reduced the flux from 190.3 to 67.9 $\mu \mathrm{g} . \mathrm{cm}^{-2} \cdot \mathrm{h}^{-1}$. Moreover, the increase in the concentration of citric acid from 0.1 to $1 \mathrm{M}$ to increase the solubility of atenolol and reverse the ratio of hydrophilic phase (ethanol: water) from 70:30 to 30:70 in ME900-1CA0.3and ME900-1CA0.7 respectively led to decrease in the flux.

\author{
In vivo transdermal of atenolol loaded microemulsion \\ penetration study
}

The transdermal bioavailability of atenolol loaded microemulsion was studied by applying each of ME1000-0.1CA and system ME1000dmso-s which showed the best in vitro flux on 4 shaved rat's skin. The penetrated amount of atenolol through the skin in plasma was quantified in $0.5 \mathrm{ml}$ collected blood samples over $24 \mathrm{~h}$ using HPLC-method (fig. 1C). The two plasma level time curves over $24 \mathrm{~h}$ are represented in fig. 7. Furthermore, elimination rate constant half-life (K10_HL), the area under the curve (AUC), the absorption rate constant half-life (K01_HL), time of maximum absorption (tmax) and maximum concentration (Cmax) were calculated using phoenix program. Results are summarized in table 5.

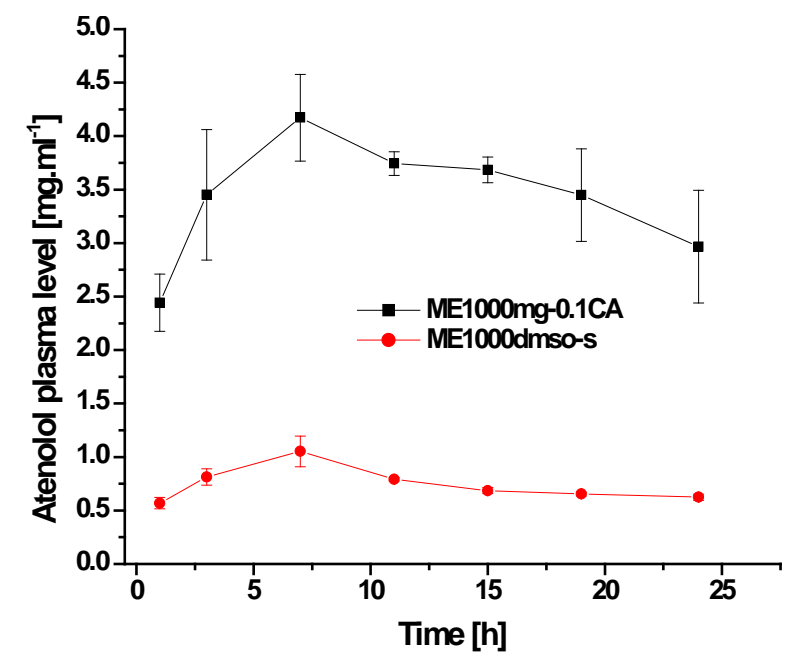

Fig. 7: Plasma level time curve of atenolol in rats from ME1000 0.1CA; and ME1000dmso-s. Data given in this fig. is presented as mean \pm SD, $\mathrm{n}=3$, SD: Standard deviation

Table 5: The different transdermal bioavailability parameters of atenolol using pheonix program including elimination rate constant half-life (K10_HL), the area under the curve (AUC), the absorption rate constant half-life (K01_HL), time of maximum absorption (tmax) and maximum concentration (Cmax) of ME1000m0.1CA and ME1000dmso-s

\begin{tabular}{lllll}
\hline Parameter & Units & ME1000-0.1CA & CV\% & ME1000dmso-s \\
\hline AUC & mg. h. ml ${ }^{-1}$ & $285.54 \pm 61.11$ & 21.40 & $39.99 \pm 8.37$ \\
K01_HL & H & $0.91 \pm 0.13$ & 14.33 & $0.99 \pm 0.25$ \\
K10_HL & H & $45 \pm 11.86$ & 26.36 & $26.17 \pm 7.59$ \\
CL_F & ml. h-1 & $1.84 \pm 0.39$ & 21.42 & $11.69 \pm 2.45$ \\
Tmax & H & $5.22 \pm 0.43$ & 8.18 & $4.85 \pm 0.69$ \\
Cmax & mg. ml ${ }^{-1}$ & $4.06 \pm 0.15$ & 3.64 & 24.86 \\
\hline
\end{tabular}

Data given in this table is presented as mean $\pm \mathrm{SD}, \mathrm{n}=3$, SD: Standard deviation

The maximum times of absorption and the absorption half-lives of the two MEs were similar. The maximum concentration of ME1000$0.1 \mathrm{CA}$ was $4.06 \mathrm{mg}^{-1}$ and in the case of ME1000dmso-s was 0.93 mg. $\mathrm{ml}^{-1}$. Also, no lag time was observed for two formulated system. Furthermore, the calculated AUC showed higher bioavailability of ME1000-0.1CA more than 7 folds in comparison toME1000dmso-s. However, the plasma level of atenolol increased rapidly and decreased very slowly to remain relatively high at over $24 \mathrm{~h}$.

\section{DISCUSSION}

Using FTIR-spectroscopy, incorporation of atenolol inside the MEs and distribution of ethanol in the external phase with IPM could be proved. Construction of three-phase diagram helps to prepare a stable homogeneous system of water and oil with as little surfactant as possible that can be diluted with water in all proportions without phase separation [30]. However, the observed shifting in required 
fractions for forming clear MEs in the three-phase diagram towards more fractions of hydrophilic phase can be explained by the change in the polarity of the hydrophilic phase because of the presence of atenolol which led in its turn to change in the interfacial tension. As a result, the solubility of the hydrophilic phase was increased after the addition of atenolol.

Furthermore, all systems had Newtonian properties with relatively low viscosity which impart them good favorable properties for penetration through the skin [31]. The viscosities of different formulations were similar and less than $0.1 \mathrm{~Pa}$. s. However, ME9001CA0.7 showed the highest viscosity compared to other MEs which may be attributed to the small amount of used surfactants $(0.1 \mathrm{ml})$ and hydrophilic phase volume $(1.4 \mathrm{ml})$. The ME900-1CA0.3 had the lowest viscosity which may be related to the hydrophilic phase composition.

The droplet size is an important factor in controlling the rate and extent of drug release as well as permeation of drugs through the skin. ME1000-0.1CA which had the smallest droplet size showed a good penetration through rat's skin and a higher flux than other formulated systems

The droplet size of the MEs varied between 100-500 nm which complied with the colloidal system's characteristics [32]. Furthermore, low droplet size of free atenolol in comparison to the same composition loaded atenolol systems gave another proof of encapsulation of atenolol inside the inner phase.

Hence, a sufficient volume of hydrophilic phase had to be used to solubilize atenolol before addition to $2 \mathrm{ml}$ of lipophilic phase, the consumed surfactant amount varied with the varying volume of encapsulated hydrophilic phase and its composition.

The in vitro transdermal using Franz diffusion cell didn't show a consistent correlation between the flux and atenolol concentration in MEs according to fick's law but was more related to MEs compositions of hydrophilic phase, surfactants type and droplet size [33].

Using $0.1 \mathrm{M}$ citric acid as buffering agent led to an increase the solubilized atenolol in ME, decrease the droplet size, decrease the zeta potential and increase in the flux. However, further increasing in citric acid concentration to $1 \mathrm{M}$ increases the incorporated atenolol and the droplet size. Hence, the flux of atenolol decreased.

DMSO as penetration enhancer didn't enhance the penetration in case of ME1000dmso-st. Conversely, DMSO enhanced the penetration of atenolol in system ME1000dmaso-s which was stabilized using span 20 only which may be attributed to the small structure of span 20 in comparison to tween 80 and hydrophilic property of tween 80 . Moreover, a greater volume of span 20 was consumed for stabilizing ME1000dmso-s in comparison to ME1000dmso-st which also may be related to a small structure of span 20. However, the developed microemulsion ME1000-0.1CA and ME1000dmso-s showed higher flux $(243.5 \pm 16.3$ and $190.3 \pm 21.3 \mu \mathrm{g}$. $\mathrm{cm}-2$. h-1 respectively) in comparison to the reported best-developed microemulsions by Dhingani et al. (140.69 $\mu \mathrm{g} . \mathrm{cm}-2$. h-1) [23]. Furthermore, the evaluated AUC (12.4 $\pm 3.06 * 10-3 \mathrm{mg}$. h. ml-1) of atenolol in ethylene-vinyl acetate (EVA) matrix system containing polyoxyethylene-2-oleyl ether was much lower than estimated in our study [17].

ME1000-0.1CA showed higher flux and bioavailability in comparison to ME1000dmso-s which may be associated to the lower droplet size and the higher concentration of atenolol in ME1000-0.1CA compared to ME1000dmso-s. Furthermore, the transdermal application of both two systems maintained a high plasma level over $24 \mathrm{~h}$ during the investigation.

\section{CONCLUSION}

The flux of atenolol didn't correlate always with the concentration of atenolol. Contrariwise, it related with surfactant nature, the composition of the inner phase or even with zeta potential. However, the composition of MEs, their influence on zeta potential and the impact of their zeta potential on the transdermal (that the nonionized form is preferable for penetration through cell membranes) need more investigation.
In the present study, atenolol could be incorporated successfully in novel microemulsions which showed rapid and high transdermal flux with a relatively constant and high plasma level of atenolol during $24 \mathrm{~h}$.

\section{AUTHORS CONTRIBUTIONS}

All the author have contributed equally

\section{CONFLICT OF INTERESTS}

Declared none

\section{REFERENCES}

1. Barrett AM, Carter J, Fitzgerald JD, Hull R, Le Count D. A new type of cardioselective adrenoceptive blocking drug. $\mathrm{Br} \mathrm{J}$ Pharmacol 1973;48:340.

2. Harry JD, Knapp MF, Linden RJ. Proceedings: antagonism by ICI 66082 of the effects of electrical stimulation on the right ansasubclavia of the dog. Br J Pharmacol 1974;50:457-8.

3. Heel RC, Brogden RN, Speight TM, Avery GS. Atenolol: a review of its pharmacological properties and therapeutic efficacy in angina pectoris and hypertension. Drugs 1979;17:425-60.

4. William H, Frishman MD. Atenolol and timolol, two new systemic Badrenoreceptor antagonists. N Engl J Med 1982;306:1456-62.

5. Fitzgerald JD, Ruffin R, Smedstad KG, Roberts R, McAinsh J. Studies on the pharmacokinetics and pharmacodynamics of atenolol in man. Eur J Clin Pharmacol 1978;13:81-9.

6. ASHP. AHFS Drug information, AHFS, MD, USA; .2002. p. 1586.

7. Kim J, Shin SC. Controlled release of atenolol from the ethylenevinyl acetate matrix. Int J Pharm 2004;273:23-7.

8. Schoellhammer CM, Blankschtein D, Langer R. Skin permeabilization for transdermal drug delivery: recent advances and future prospects. Expert Opin Drug Delivery 2014;11:393-407.

9. Shingade GM, Quazi A, Sabale PM, Grampurohit ND, Gadhave MV, Jadhav SL, et al. Review on: recent trend on transdermal drug delivery system. J Drug Delivery Ther 2012;2:66-75.

10. Reeves PR, Barnfield DJ, Longshaw S. Disposition and metabolism of atenolol in animals. Xenobiotica 1978;8:305-11.

11. Inal $\mathrm{O}$, Kiliçarslan $\mathrm{M}$, Ari $\mathrm{N}$, Baykara $\mathrm{T}$. In vitro and in vivo transdermal studies of atenolol using iontophoresis. Acta Pol Pharm 2008;65:29-36.

12. Anroop B, Ghosh B, Parcha V, Khanam J. Transdermal delivery of atenolol: effect of prodrugs and iontophoresis. Curr Drug Delivery 2009;6:280-90.

13. Nair A, Reddy C, Jacob S. Delivery of a classical antihypertensive agent through the skin by chemical enhancers and iontophoresis. Skin Res Technol 2009;15:187-94.

14. Keerthi H, Panakanti PK, Yamsani MR. Design and characterization of atenolol transdermal therapeutic systems: enhancement of permeability via iontophoresis. PDA J Pharm Sci Technol 2012;66:318-32.

15. Pawar KR, Smith F, Kolli CS, Babu RJ. Effect of lipophilicity on microneedle-mediated iontophoretic transdermal delivery across human skin in vitro. J Pharm Sci 2013;102:3784-91.

16. Macgregor JM, Rush JE, Rozanski EA, Boothe DM, Belmonte A, Freeman LM. Comparison of pharmacodynamic variables following oral versus transdermal administration of atenolol to healthy cats. Am J Vet Res 2008;69:39-44.

17. Shin SC, Choi JS. Enhanced bioavailability of atenolol by transdermal administration of the ethylene-vinyl acetate matrix in rabbits. Eur J Pharm Biopharm 2003;56:439-43.

18. Amjad M, Ehtheshamuddin M, Chand S, Hanifa MS, Asia R, Kumar GS. Formulation and evaluation of transdermal patches of atenolol. ARPB 2011;2:109-19.

19. Vishal Y, Prakash J, Kishor K, Anjali B, Shailaja D. Preparation and evaluation microemulsion containing an antihypertensive drug. Int J Appl Pharm 2018;10:138-46.

20. Sahar MF, Shadeed G, El-Syed AK, Gehad AA, Mamdouh MG, Sohier AE. Formulation and evaluation of etodolac lecithin organogel transdermal delivery systems. Int J Pharm Pharm Sci 2015;7:325-34.

21. Lavanya N, Aparna C, Umamahesh B. Formulation and evaluation of glipizide microemulsion. Int J Pharm Pharm Sci 2016;8:171-6. 
22. Heuschkel S, Goebel A, Neubert RHH. Microemulsions-modern colloidal carrier for dermal and transdermal drug delivery. J Pharm Sci 2008;97:603-31.

23. Dhingani A, Patel J, Garala K, Raval M, Dharamsi A. Quality by design approach for the development of W/O Type microemulsion based transdermal systems for atenolol. J Disper Sci Technol 2014;35:619-40.

24. Prapaporn B, Karen K, Anja G, Thomas R, Varaporn BJ. Characterization of microemulsion structures in the pseudoternary phase diagram of isopropyl Palmitate/Water/Brij 97:1-Butanol. AAPS Pharm Sci Tech 2006;7:99-104.

25. United States Pharmacopeia Convention. United States Pharmacopeia and National Formulary (USP 34-NF 29). United States Pharmacopeia Convention; 2010.

26. Guidance notes on dermal absorption, OECD Environment, Health and Safety Publications, Series on Testing and Assessment, No. 156, ENV/JM/MONO; 2011. p. 36. Available from: http://www.oecd.org/officialdocuments/publicdisplay documentpdf/?cote $=\mathrm{env} / \mathrm{jm} / \mathrm{mono}(2011) 36$ anddoclanguage= en.
27. Li CJ, Obata Y, Higashiyama K, Nagai T, Takayama K. Effect of 1O-ethyl3--butylcyclohexanol on the skin permeation of drugs with different physicochemical characteristics. Int J Pharm 2003;259:193-8.

28. Council of Europe. European Pharmacopoeia. 4rd edn. Council of Europe, Strasbourg; 2003.

29. Barbara HS. Infrared spectroscopy: fundamentals and applications. Chichester, UK: John Wiley and Sons Ltd; 2004.

30. Kahlweit M, Strey R, Firman P, Haase D. Phase behavior of ternary systems: H20-0il-Nonionic surfactant as a neartricritical phenomenon. Langmuir 1985;1:281-8.

31. Neubert RHH. Potentials of new nanocarriers for dermal and transdermal drug delivery. Eur J Pharm Biopharm 2011;77:1-2.

32. David A. Microemulsions. In: Kreuter J. (Ed) Colloidal drug delivery systems, drug and the pharmaceutical science, a series of textbooks and monographs. New York, USA: Marcel Dekker; 1994. p. 31-65.

33. Kanjananimmanont S, Ge X, Mupparapu K, Rao G, Potts R, Tolosa L. Passive diffusion of transdermal glucose: noninvasive glucose sensing using a fluorescent glucose binding protein. J Diabetes Sci Technol 2014;8:291-8. 